\title{
Student public commitment in a school-based diabetes prevention project: impact on physical health and health behavior
}

Lynn L DeBar ${ }^{1 *}$, Margaret Schneider ${ }^{2}$, Kimberly L Drews ${ }^{3}$, Eileen G Ford ${ }^{4}$, Diane D Stadler ${ }^{5}$, Esther L Moe ${ }^{5}$, Mamie White ${ }^{6}$, Arthur E Hernandez ${ }^{7}$, Sara Solomon ${ }^{8}$, Ann Jessup $^{9}$ and Elizabeth M Venditti ${ }^{10}$, for the HEALTHY study group

\begin{abstract}
Background: As concern about youth obesity continues to mount, there is increasing consideration of widespread policy changes to support improved nutritional and enhanced physical activity offerings in schools. A critical element in the success of such programs may be to involve students as spokespeople for the program. Making such a public commitment to healthy lifestyle program targets (improved nutrition and enhanced physical activity) may potentiate healthy behavior changes among such students and provide a model for their peers. This paper examines whether student's "public commitment"-voluntary participation as a peer communicator or in studentgenerated media opportunities-in a school-based intervention to prevent diabetes and reduce obesity predicted improved study outcomes including reduced obesity and improved health behaviors.
\end{abstract}

Methods: Secondary analysis of data from a 3-year randomized controlled trial conducted in 42 middle schools examining the impact of a multi-component school-based program on body mass index (BMI) and student health behaviors. A total of 4603 students were assessed at the beginning of sixth grade and the end of eighth grade. Process evaluation data were collected throughout the course of the intervention. All analyses were adjusted for students' baseline values. For this paper, the students in the schools randomized to receive the intervention were further divided into two groups: those who participated in public commitment activities and those who did not. Students from comparable schools randomized to the assessment condition constituted the control group.

Results: We found a lower percentage of obesity (greater than or equal to the $95^{\text {th }}$ percentile for BMI) at the end of the study among the group participating in public commitment activities compared to the control group (21.5\% vs. $26.6 \%, p=0.02$ ). The difference in obesity rates at the end of the study was even greater among the subgroup of students who were overweight or obese at baseline; $44.6 \%$ for the "public commitment" group, versus 53.2\% for the control group $(p=0.01)$. There was no difference in obesity rates between the group not participating in public commitment activities and the control group (26.4\% vs. $26.6 \%)$.

Conclusions: Participating in public commitment activities during the HEALTHY study may have potentiated the changes promoted by the behavioral, nutrition, and physical activity intervention components.

Trial Registration: ClinicalTrials.gov number, NCT00458029

\footnotetext{
* Correspondence: lynn.debar@kpchr.org

'Kaiser Permanente Center for Health Research, 3800 North Interstate Ave,

Portland, OR 97227, USA

Full list of author information is available at the end of the article
} 


\section{Background}

Epidemic rates of childhood and adolescent obesity represent a serious public health concern. Obesity prevalence among youth remains at historically high levels with $16.0 \%$ of 6 to 19 year olds overweight and $18.7 \%$ obese [1]. Higher rates are reported among economically disadvantaged and minority youth [1-3]. The health and economic burden of such morbidity is substantial [4], including, most seriously, risk for type 2 diabetes $[4,5]$; hence interventions aimed at preventing and controlling childhood obesity are increasingly important. Because schools are uniquely positioned to promote healthful eating and physical activity, school-based interventions provide an unparalleled opportunity to reach many of the highest risk youth $[6,7]$. Many programs have been designed and launched to address these targets [7-10], yet outcomes have been disappointing $[7,11,12]$. Finding ways to increase students' commitment to program goals, particularly strategies that leverage the social environment and peer influence of young adolescents, may contribute to better outcomes and more sustained and generalized effects.

Strong theoretical and empirical evidence supports the supposition that individuals who make a public commitment to a behavioral goal exhibit greater effort and persistence. This supposition, investigated in both laboratory and field settings, is grounded in work demonstrating that public commitment to an attitudinal position enhances resistance to persuasion [13-15] as well as in the research on strategic self-presentation [16]. Salancik [17] posited that individuals are strongly motivated to appear rational and consistent, and that "one of the simplest ways to commit yourself to a course of action is to go around telling all of your friends that you are definitely going to do something." College students randomly assigned to make a public (vs. private) commitment to a goal demonstrated stronger commitment [18], greater goal-consistent behavior [19], more effort expended to reach the goal [20], and greater progress toward the goal [21]. These laboratorybased studies show that individuals who publicly commit to a performance goal are more likely to enact behaviors that move them toward their goal compared to those who make a private statement of intentions. In addition, Wilson and colleagues [22] suggest that there is a "carry-over effect" whereby an individual's self presentation strongly influences their private self-appraisal and, in turn, subsequent behavior. These authors suggest that this effect is due to cognitive dissonance [23,24] (altering self-concept to match how one publicly presents oneself to reduce dissonance when one's private self-concept and public selfpresentation are discrepant) and biased scanning [25] (in which beliefs congruent with one's actions are most salient and primed).

Outside the controlled laboratory environment, public commitment to a behavioral goal has also been shown to influence health-related behaviors. More than fifty years ago, classic studies found those who publicly agreed to change their dietary habits were more likely to do so and to sustain these changes than were those who made no such commitment $[26,27]$. Such decisional processes were also shown in studies with youth [28]. More recently, making a public commitment has been shown to increase adherence to medicinal prescriptions [29], and has been incorporated into school-based healthbehavior interventions, such as smoking prevention programs [30-32] and dietary interventions [33]. Most pertinent to the current analysis, Birnbaum and colleagues [33] reported that in a middle school-based nutrition intervention, peer leaders were the only student participants to demonstrate consistent and significant improvements in fruit-and-vegetable consumption and lower-fat food choices. The authors suggest that peer leaders may have changed their behavior to reduce cognitive dissonance or to "walk the talk", given that they delivered eating-related messages to classmates and may have felt pressure (conscious or not) to make their behavior conform to those messages. As noted by Wilson and colleagues [22], studies examining the role of commitment in producing behavior change suggest that "individuals who freely choose to commit themselves publicly to a particular identity ('I eat healthy') and a course of action should be more likely to do so than individuals who only hold such beliefs privately".

For the current report, students in the HEALTHY study who visibly and voluntarily aligned themselves with HEALTHY-sponsored activities can be said to have made a public commitment to the study's behavioral goals (being more active and consuming nutritious foods and beverages). The ways that students demonstrated public commitment included a variety of activities, such as: assisting with classroom activities, helping with grade and/or school-wide events such as taste tests and cafeteria learning events, and inviting peers' participation; making public-address announcements; wearing studyrelated $t$-shirts identifying them as peer leaders; and being featured in print media posted throughout the school. Each demonstration of public commitment to the study's behavioral goals manifested the student's adoption of his or her peer leadership role. Here we examine whether making a public commitment to the HEALTHY program over the course of the intervention improved study outcomes including reduced obesity and improved health behaviors.

\section{Methods}

\section{Study design}

HEALTHY was a multi-center primary prevention trial designed to reduce risk factors for type 2 diabetes in adolescents. The overall trial design, and the communications 
component specifically, are described in detail elsewhere [34,35]. HEALTHY was a cluster-design trial [36] where schools were the unit of randomization and intervention. The primary outcome of the study was body mass index (BMI) percentile. Data were collected at both the school and the student level, but only from those individuals providing assent and parental informed consent. A cohort of 4603 sixth grade students who were enrolled and for whom data were available at baseline and at the end of their eighth grade year were included in the primary outcome analyses. Overall findings at the end of eighth grade included greater reductions in the intervention schools on BMI z-score, percentage of students with waist circumference at or above the $90^{\text {th }}$ percentile, fasting insulin levels $(\mathrm{P}=0.04$ for all comparisons), and prevalence of obesity $(\mathrm{P}=0.05)[37]$.

The HEALTHY intervention, delivered over five semesters (Spring 2007, Fall 2007, Spring 2008, Fall 2008, Spring 2009) comprised four components: 1) nutrition; 2) physical education; 3) behavior; and 4) communications. The four intervention components were integrated by a series of themes targeting specific behaviors and building on each other (i.e., consuming water versus added sugar beverages; increasing physical activity and reducing sedentary behavior; consuming high-quality and reducing lowquality food; achieving energy balance; and making healthy choices for life). These themes are described elsewhere [34,38-40]. Theme-based communications campaigns [34] integrated and supported each aspect of the HEALTHY intervention and used core elements, such as branding, posters, banners, visual and verbal messaging; student events and student-generated media; distribution of thematic branded items, such as water bottles and pedometers; and involvement of student peer communicators (SPC, described in more detail below). Communications intervention strategies, including public commitment opportunities for students, were intended to strengthen the impact of all HEALTHY intervention components.

\section{Study Participants}

Forty-two schools participated in the study (21 matched pairs randomized to intervention and control conditions), representing a broad geographic distribution (California, North Carolina, Oregon, Pennsylvania, and Texas). Major inclusion criteria for schools were at least $50 \%$ of children eligible for federally subsidized, free, or reducedpriced meals and/or at least $50 \%$ of students whose ethnicity was Black or Hispanic. To be eligible for the study cohort, students had to: be enrolled in $6^{\text {th }}$ grade in Fall 2006; provide data to determine BMI percentile at baseline; and have no conditions that would preclude active participation in physical education classes. Fourteen students who had a previous diagnosis of diabetes at baseline and one student who was identified as meeting the criteria for diabetes at baseline were excluded. Almost two-thirds of students at the targeted schools agreed to participate in the data collection $(58.9 \%)$ and there was little difference between those who consented and assented and those who did not with respect to mean $( \pm$ SD) BMI (the weight in kilograms divided by the square of the height in meters) $(22.6 \pm 8.7$ and $21.8 \pm 5.3$, respectively), mean age (11.3 \pm 0.6 and $11.3 \pm 0.7$ years $)$, race or ethnic group $(70.5 \%$ and $72.9 \%$ black or Hispanic), or sex (47.7\% and $53.0 \%$ boys) [35]. All children in the intervention schools and grades received the intervention. The study was approved by each participating university's Institutional Review Board (IRB). Recruitment procedures, described in detail elsewhere [41], were identical for intervention and control schools.

\section{Public Commitment Activities: Student Peer Communicators}

Students in the cohort grade known as student peer communicators (SPC) endorsed and promoted study activities to their peers and provided informal feedback to HEALTHY study staff. Participation was voluntary and the number of SPCs at each school depended on school size and other local considerations. SPCs were selected through a combination of self- and peer-nomination. The SPC was seen as a potential "influencer" or one who was able to promote key study messages in a meaningful way to peers. SPCs "connected" students in the cohort grade to the HEALTHY intervention through the dissemination of study messages, facilitation of classroom-based, cohort- and school-wide activities, and informal communication with their peers about study activities [34]. All SPCs attended a one-hour initial training that was standardized by supplying study staff with a centrallydesigned PowerPoint presentation. The initial training outlined the required tasks, skills, and procedures, and included the voluntary recitation of the following pledge:

"I promise to be a HEALTHY leader in my school. I will learn about being HEALTHY and share what I learn with my friends, my school, my family and my community. I will be positive and encouraging. I will set an example to the best of my ability by living well in every way. I am HEALTHY!

This initial training was followed in subsequent weeks by supplemental 30-minute trainings specific to each intervention activity in which each SPC participated. SPCs received training for each activity they selected. The study protocol dictated that students would be required to spend no more than one hour per week of time outside class, however, all SPCs were expected to be active in study-related events throughout the duration of their participation. Table 1 describes specific activities 


\begin{tabular}{|c|c|c|c|}
\hline & $\%(\mathrm{~N})$ & & \\
\hline \multicolumn{4}{|l|}{ Type of Activity } \\
\hline SPC only & $13.8 \%(318)$ & & \\
\hline SGM only & $13.5 \%(312)$ & & \\
\hline SPC/SGM & $8.9 \%(205)$ & & \\
\hline none & $63.8 \%(1472)$ & & \\
\hline \multicolumn{4}{|l|}{$\begin{array}{l}\text { Semesters of } \\
\text { Participation }\end{array}$} \\
\hline 1 & $12.8 \%(295)$ & & \\
\hline 2 & $12.7 \%(294)$ & & \\
\hline 3 & $6.9 \%(158)$ & & \\
\hline 4 & $3.3 \%(75)$ & & \\
\hline \multirow[t]{2}{*}{5} & $0.6 \%(13)$ & & \\
\hline & $\begin{array}{l}\text { Opportunities per } \\
\text { semester for } \\
\text { participation }\end{array}$ & $\begin{array}{c}\text { \# of students } \\
\text { participating per school each } \\
\text { semester } \\
\text { M (SD) }\end{array}$ & $\begin{array}{l}\text { Frequency of participation per student each } \\
\text { semester } \\
\text { M (SD) }\end{array}$ \\
\hline \multicolumn{4}{|l|}{$\begin{array}{l}\text { Public Commitment } \\
\text { Activities }\end{array}$} \\
\hline Event specialist & $1-6$ & $6.8(3.8)$ & $1.9(0.9)$ \\
\hline News reporter & $1-11$ & $4.6(3.2)$ & $2.6(2.1)$ \\
\hline Classroom assistant & $1-26$ & $9.2(2.8)$ & $7.6(3.3)$ \\
\hline Photojournalist & $1-4$ & $3.4(2.3)$ & $1.3(0.5)$ \\
\hline SGM & 1 & $13.7(4.6)$ & N/A \\
\hline
\end{tabular}

and shows the frequency with which students served in these roles.

Public Commitment Activities: Student-Generated Media As part of the communications campaign, identical centrally-produced posters, signage, and cafeteria-line messages were displayed at all intervention schools throughout the first year of the intervention. One year into the intervention, in the spring of $7^{\text {th }}$ grade, the communications approach changed to involve students in the process. This shift involved creation of "Student-Generated Media" (SGM) as the core of the communications approach. Study-wide poster and DVD templates consistent with each semester's intervention theme were provided to the local study sites' staff, which then conducted school-specific photo shoots and allowed students to provide photographs, artwork, audio clips, and video clips for use in the intervention's communications campaign. Accordingly, communications materials distributed throughout the latter stages of the intervention depicted study students' own experiences and highlighted their public commitment to the study and its healthy lifestyle goals. Because all SGMcreated materials were posted for a minimum of several weeks in a given semester, participants' public commitment to the HEALTHY program was evident over a substantial portion of the semester even if the creation of a given poster required a relatively shorter time commitment. A more complete description of the development and implementation of this intervention element is provided elsewhere [34]. Participation in these activities was voluntary and required prior parental approval.

\section{Study Measures}

Demographic, behavioral, and anthropometric data were collected at the study onset (beginning of $6^{\text {th }}$ grade) and conclusion (end of 8th grade). A comprehensive description of all study measures is included elsewhere [35]. For this report we also reviewed process evaluation data obtained throughout the study, including: qualitative student feedback obtained via structured interviews and focus groups; SPC tracking logs recording each time an SPC received training or participated in a study-related activity; and SGM logs identifying students whose pictures, art-work or video clips were used in study-related communications materials. These data were collected at each intervention school every semester. A complete description of process measures for the study was published previously [42]. 


\section{Analysis Plan}

A total of 4603 students provided complete and valid primary outcome data in both $6^{\text {th }}$ and $8^{\text {th }}$ grade. Smaller student subsamples also provided complete and valid data for waist circumference, dietary intake, and fitness in $6^{\text {th }}$ and $8^{\text {th }}$ grades. Descriptive statistics with means (M) and standard deviations (SD) for continuous measures and percentages for categorical variables are presented. While the school was the unit of randomization and intervention, for this report we further divided the students in intervention schools into two groups: those who participated in public commitment activities (PC) and those who did not participate (NPC). Hence, for this report we examined differences between the three groups of PC, NPC and control. It should be noted that inclusion in the PC and NPC group was not determined by randomization but rather by self-selection. General linear mixed models (GLMM) were used to analyze differences between these groups or clusters $[43,44]$ with the covariance structure appropriately adjusting for variability both between cluster and also within cluster [36,45]. This was accomplished by using the PROC MIXED procedure for continuous data and the PROC GLIMMIX procedure for categorical data incorporating a random effect for school at baseline and for group assignment within school at end-of-study into the model. Model selection was performed by including characteristic variables, where appropriate, into the model both alone and as an interaction with group assignment and any variables with a p-value greater than 0.10 in either instance were removed from the overall model. Models for demographic and anthropometric baseline variables were unadjusted, and models for anthropometric end-of-study variables were adjusted only for their baseline value (e.g. models for end of study BMI percentile contained the baseline BMI percentile as a covariate). Models for dietary intake and fitness variables were adjusted for baseline value at the end of study and for gender at both baseline and end-of-study (e.g., models for baseline fitness had gender as a covariate while the models for fitness at the end of study contained both gender and the baseline number of laps as covariates). Sexual maturation or pubertal stage was determined using the gender-specific pubertal development scale [46,47] from which Tanner score was determined [48]. When the resulting Tanner score was included in the exploratory models for fitness, it was found to contribute very little and its inclusion did not affect the overall fitness results. Hence, the final models were not adjusted for Tanner score. Due to skewness and presence of zeros, the dietary intake variables were transformed using the square root to ensure approximately normal distributions of the variables. When statistically significant group differences were found, pairwise comparisons were carried out to evaluate meaningful differences between categories. To account for multiple testing and protect the family-wise error rate, a modified sequentially rejective Bonferroni procedure was used to adjust p-values [49].

Consistent with the recently published report examining main outcomes of the study [37], the same outcomes were assessed in a high-risk subgroup of overweight or obese (BMI > 85th percentile) students at baseline; 50\% of participating students met this criterion (Table 2).

As previously reported [36], the power calculation for this study was based on detecting change in the prevalence of overweight and obesity. As such the p-values reported within this paper are associated with exploratory, post-hoc analyses, represent findings associated with secondary outcomes, and are provided to help facilitate the interpretation of the data only with alpha set at .05. All analyses were performed using SAS version 9.2 (SAS Institute, Cary, NC).

\section{Results}

\section{Baseline Characteristics}

Table 2 compares the baseline characteristics of the three groups: consented students in the intervention schools who did and did not participate in public commitment activities (i.e., PC vs. NPC) and consented students in the control schools. Comparisons are presented for the entire sample and for the subgroup of students who were overweight or obese at baseline. Few differences emerged at baseline between the groups. For the overall sample, a significantly smaller proportion of males were in the PC group than was anticipated given the number of males in the sample $(41.4 \%$ versus $50.7 \%$ in the NPC group and $47.1 \%$ in the control group, $\mathrm{p}<0.001)$. Hence, gender was added as a covariate into the outcome analyses for student health behaviors (see Tables 2 and 3). However, because anthropometric variables (BMI percentile, waist circumference $\geq 90^{\text {th }}$ percentile) already adjust for gender, it was not included in the outcome analyses of these variables to prevent over-parameterization. The PC group scored higher on the fitness measure, completing more laps $(\mathrm{M}=22.2$ $[\mathrm{SD}=12.2])$ compared to the NPC group $(\mathrm{M}=20.4$ [SD = $11.6], \mathrm{p}=.001)$. Although statistically significant, the modest difference in number of laps completed between the groups suggests a non-meaningful fitness difference at study onset $[50,51]$. Baseline fitness was added into the models as a covariate with only slight changes in overall significance detected. For this reason fitness was not retained in the final models. There were no significant differences on nutritional variables (fruit/vegetable and added sugar beverage consumption) between either of the intervention groups (PC, NPC) and the control group. Finally, there were no differences in baseline characteristics or health behaviors between the PC, NPC and control groups when restricting the sample to those who were overweight or obese at baseline. 
Table 2 Baseline Measures by Participant Group

\begin{tabular}{|c|c|c|c|c|c|c|c|c|}
\hline & \multicolumn{4}{|c|}{ Overall $(\mathrm{N}=4603)$} & \multicolumn{4}{|c|}{ Baseline $\mathrm{BMI} \geq 85^{\text {th }}$ percentile $(\mathrm{N}=2292)$} \\
\hline & $\mathrm{PC}(\mathrm{N}=835)$ & NPC (N = 1472) & Control $(\mathrm{N}=2296)$ & & $P C(N=392)$ & NPC (N = 768) & Control $(\mathrm{N}=1132)$ & \\
\hline & Mean $(\mathrm{SD})$ or $\%$ & Mean (SD) or \% & Mean (SD) or \% & p-value & Mean (SD) or \% & Mean $(\mathrm{SD})$ or $\%$ & Mean (SD) or \% & p-value \\
\hline \multicolumn{9}{|l|}{ Student Characteristics } \\
\hline Age in years, $M(S D)$ & $11.2(0.5)$ & $11.3(0.5)$ & $11.3(0.5)$ & 0.08 & $11.2(0.5)$ & $11.2(0.5)$ & $11.3(0.6)$ & 0.14 \\
\hline$\%$ male $^{1}$ & $41.4 \%$ & $50.7 \%$ & $47.1 \%$ & $<0.001$ & $47.2 \%$ & $52.2 \%$ & $50.4 \%$ & 0.24 \\
\hline Race/Ethnicity & & & & 0.58 & & & & 0.40 \\
\hline Hispanic & $51.0 \%$ & $57.0 \%$ & $53.5 \%$ & & $53.8 \%$ & $60.7 \%$ & $56.7 \%$ & \\
\hline Black & $22.5 \%$ & $19.1 \%$ & $15.7 \%$ & & $19.9 \%$ & $17.7 \%$ & $16.2 \%$ & \\
\hline White & $18.6 \%$ & $16.2 \%$ & $21.6 \%$ & & $17.9 \%$ & $14.3 \%$ & $18.6 \%$ & \\
\hline Other & $7.9 \%$ & $7.7 \%$ & $9.2 \%$ & & $8.4 \%$ & $7.3 \%$ & $8.5 \%$ & \\
\hline BMI Percentile, M (SD) & $71.5(28.1)$ & $74.1(27.5)$ & $72.3(28.6)$ & 0.08 & $94.9(4.1)$ & $95.1(4.0)$ & $95.1(4.1)$ & 0.66 \\
\hline $\mathrm{BMI} \geq 95^{\text {th }}$ Percentile & $27.8 \%$ & $31.4 \%$ & $30.4 \%$ & 0.20 & $59.2 \%$ & $60.2 \%$ & $61.7 \%$ & 0.61 \\
\hline Waist Circumference $\geq 90^{\text {th }}$ Percentile & $28.0 \%$ & $30.3 \%$ & $28.6 \%$ & 0.47 & $59.3 \%$ & $57.7 \%$ & $57.7 \%$ & 0.92 \\
\hline \multicolumn{9}{|l|}{ Family Characteristics } \\
\hline Highest Household Education ${ }^{3}$ & & & & 0.25 & & & & 0.28 \\
\hline$\leq$ HS Graduate & $48.7 \%$ & $53.6 \%$ & $51.5 \%$ & & $49.1 \%$ & $56.5 \%$ & $54.9 \%$ & \\
\hline$\geq$ Some College & $51.3 \%$ & $46.4 \%$ & $48.5 \%$ & & $51.0 \%$ & $43.5 \%$ & $45.1 \%$ & \\
\hline Positive Reported Family History of Diabetes & $14.5 \%$ & $11.4 \%$ & $13.4 \%$ & 0.08 & $18.9 \%$ & $14.2 \%$ & $17.7 \%$ & 0.07 \\
\hline \multicolumn{9}{|l|}{ Student Health Behaviors } \\
\hline Fruits and Vegetables (servings/day), M (SD) & $2.6(2.3)$ & $2.7(2.4)$ & $2.8(2.6)$ & 0.64 & $2.6(2.2)$ & $2.6(2.3)$ & $2.8(2.6)$ & 0.37 \\
\hline Added Sugar Beverages (oz/day), M (SD) ${ }^{4}$ & $11.5(14.4)$ & $11.1(13.2)$ & $10.8(12.4)$ & 0.97 & $10.9(13.4)$ & $11.1(13.4)$ & $10.2(11.9)$ & 0.65 \\
\hline Fitness (\# of laps), M (SD) $)^{7,8}$ & $22.2(12.2)$ & $20.4(11.6)$ & $21.4(12.3)$ & 0.0043 & $17.2(9.8)$ & $16.0(8.5)$ & $16.1(8.3)$ & 0.15 \\
\hline
\end{tabular}

PC = group of intervention school students engaged in public commitment activities, NPC = group of intervention students not engaged in public commitment activities

${ }^{1}$ For overall sample, analyses of $\%$ male: PC vs. NPC, $p=<0.001$; PC vs. Control, $p=0.02 ;$ NPC vs. Control, $p=0.09$

2 "Other" race/ethnicity not used in the analysis;

${ }^{3} \mathrm{~N}=4471$ for overall analyses and $\mathrm{N}=2236$ for $\mathrm{BMI} \geq 85^{\text {th }}$ percentile subgroup due to missing data;

${ }^{4} \mathrm{~N}=3908$ for overall analyses and $\mathrm{N}=1937$ for $\mathrm{BMI} \geq 85^{\text {th }}$ percentile subgroup due to missing data; ${ }^{5}$ adjusted for gender;

${ }^{6} \mathrm{~S}$ quare root transformation used for analysis

${ }^{7} \mathrm{~N}=4157$ for overall analyses and $\mathrm{N}=2069$ for $\mathrm{BMI} \geq 85^{\text {th }}$ percentile subgroup due to missing data;

${ }^{8}$ For overall sample, analyses of fitness: PC vs. NPC, $p=0.001 ;$ PC vs. Control, $p=1.00 ;$ NPC vs. Control, $p=0.377$ 
Table 3 Anthropometric and Health Behavior Outcomes by Participant Group

\begin{tabular}{|c|c|c|c|c|c|c|c|c|}
\hline & \multicolumn{4}{|c|}{ Overall $(\mathrm{N}=4603)$} & \multicolumn{4}{|c|}{ Baseline $\mathrm{BMI} \geq 85^{\text {th }}$ percentile $(\mathrm{N}=2292)$} \\
\hline & PC $(\mathrm{N}=835)$ & NPC $(N=1472)$ & Control (N = 2296) & & $P C(N=392)$ & NPC (N = 768) & Control $(\mathrm{N}=1132)$ & \\
\hline & Mean $(\mathrm{SD})$ or $\%$ & Mean (SD) or \% & Mean (SD) or \% & p-value & Mean (SD) or \% & Mean (SD) or \% & Mean (SD) or \% & $\mathrm{p}$-value \\
\hline BMI Percentile, M (SD) & $70.9(26.9)$ & $73.2(26.3)$ & $72.6(26.7)$ & $0.20^{1}$ & $91.3(9.7)$ & $91.7(9.9)$ & $92.2(8.9)$ & $0.17^{1}$ \\
\hline $\mathrm{BMI} \geq 95^{\text {th }}$ Percentile & $21.4 \%$ & $26.4 \%$ & $26.6 \%$ & $0.02^{1}$ & $44.6 \%$ & $50.1 \%$ & $53.2 \%$ & $0.01^{1}$ \\
\hline Waist Circumference $\geq 90^{\text {th }}$ Percentile & $19.7 \%$ & $22.2 \%$ & $22.7 \%$ & $0.07^{1}$ & $40.4 \%$ & $41.8 \%$ & $45.1 \%$ & $0.05^{1}$ \\
\hline \multicolumn{9}{|l|}{ Student Health Behaviors } \\
\hline Fruits and Vegetables (servings/day), M (SD) ${ }^{4}$ & $2.4(2.0)$ & $2.4(2.1)$ & $2.3(2.0)$ & $0.23^{5}$ & $2.4(2.2)$ & $2.3(2.0)$ & $2.3(2.1)$ & $0.62^{5}$ \\
\hline Added Sugar Beverages (oz/day), M (SD) ${ }^{4}$ & $12.5(12.3)$ & $13.5(13.9)$ & $14.3(15.2)$ & $0.31^{5}$ & $10.9(11.0)$ & $13.0(13.3)$ & $12.9(14.2)$ & $0.20^{5}$ \\
\hline Fitness (\# of laps), M (SD) ${ }^{7,8}$ & $28.3(17.7)$ & $26.6(16.5)$ & $27.6(17.3)$ & $0.42^{5}$ & $25.3(16.2)$ & $23.1(14.8)$ & $22.9(14.9)$ & $0.35^{5}$ \\
\hline
\end{tabular}

$\mathrm{PC}=$ group of intervention school students engaged in public commitment activities, NPC = group of intervention students not engaged in public commitment activities

Adjusted for baseline value

${ }^{2}$ For overall sample, analyses of BMI $\geq 95^{\text {th }}$ percentile: PC vs. NPC, $p=.05$; PC vs. Control, $p=0.02$; NPC vs. Control, $p=0.37$. For high risk (baseline $B M I \geq 85^{\text {th }}$ percentile) analyses of $B M I \geq 95^{\text {th }}$ percentile: PC vs. NPC, $\mathrm{p}=.05 ; \mathrm{PC}$ vs. Control, $\mathrm{p}=0.01$; NPC vs. Control, $\mathrm{p}=.27$

${ }^{3} \mathrm{~N}=4587$ for overall analyses and $\mathrm{N}=2282$ for $\mathrm{BMI} \geq 85^{\text {th }}$ percentile subgroup due to missing data

${ }^{4} \mathrm{~N}=3908$ for overall analyses and $\mathrm{N}=1937$ for $\mathrm{BMI} \geq 85^{\text {th }}$ percentile subgroup due to missing data

${ }^{5}$ Adjusted for baseline value and gender; ${ }^{6}$ square root transformation used for analysis;

${ }^{7} \mathrm{~N}=4157$ for overall analyses and $\mathrm{N}=2069$ for $\mathrm{BMI} \geq 85^{\text {th }}$ percentile subgroup due to missing data 


\section{Public Commitment Activity}

Table 1 summarizes student participation in public commitment activities. Thirty six percent of consented students in intervention schools participated in some form of public commitment activity (the PC group), with approximately equal numbers participating in SPC activities (13.8\%) and SGM activities (13.5\%) and a smaller proportion participating in both $(8.9 \%)$. In addition, Table 1 suggests broad involvement across the available activities. Examination of the interview and focus group data obtained through process evaluation confirms that the activities we classified as evidence of public commitment were, in fact, noticed and remembered by students in the intervention schools. In interviews conducted each semester, approximately $90 \%$ of students consistently reported knowing one or more SPC at their school, and more than $60 \%$ of students suggested that the SPCs were instrumental in helping them make healthier lifestyle choices. Moreover, the interviews indicated that the student-generated media were considerably more salient than the centrally-produced materials featured in the earlier semesters. Across the two semesters spanning the transition from centrally-produced to student-generated media, there was a roughly $50 \%$ increase $(48 \%$ to $74 \%)$ in the proportion of interviewed students who, unprompted, reported noticing study posters throughout the schools.

\section{Outcome Analyses}

Table 3 presents anthropometric and health behavior outcomes at the end of the study, and compares the PC group, the NPC group, and the control group. Within the overall study, including all 4603 consented students, a lower proportion of the PC group was obese at the end of the study compared to the control group ( $21.4 \%$ vs. $26.6 \%$; $\mathrm{p}=.02)$. In contrast, there was no difference in obesity rates between the NPC group and the control group (26.4\% vs. $26.6 \% ; p=.37$ ). In other words, the data suggest the intervention had no effect on the NPC group, but reduced obesity prevalence within the $\mathrm{PC}$ group. At the end of the study, the difference in obesity prevalence between the PC group (21.4\%) and the NPC group (26.4\%) approached significance $(\mathrm{p}=.05)$. Each outcome variable was adjusted for baseline values.

The differences in obesity prevalence were even greater among the subgroup of students who were either overweight or obese at baseline. In this subgroup analysis, the PC group had lower prevalence of obesity (44.6\%) at the end of study compared to the control group (53.2\%; p = 0.01 ). There was no difference in this subgroup analysis between obesity rates for the NPC group (50.1\%) and the control group (53.2\%; $\mathrm{p}=0.27$ ). As with the analysis of the total study sample, when the analysis was limited to the students who were already overweight or obese at baseline, the intervention reduced the prevalence of obesity within the PC group but not within the NPC group. Finally, in the subgroup analysis, the difference in obesity prevalence at the end of study between the PC group (44.6\%) and the NPC group (50.1\%) approached significance $(\mathrm{p}=.05)$. Again, these analyses were adjusted for the corresponding baseline value.

We found an overall significant effect of group on waist circumference at or above the $90^{\text {th }}$ percentile. However, adjusted pairwise comparison analyses did not suggest statistically significant differences between the groups. Analogous analyses of student health behaviors revealed no overall effect of group on fitness or nutrition measures; this lack of effect extended to both intervention groups, regardless of their participation in public commitment activities.

\section{Dose Analyses}

Finally, to examine the relationship between greater involvement in public commitment activities and improved anthropometric and health behavior outcomes, we totaled the number of semesters that each intervention student participated in any public commitment activities. Students could participate in a maximum of five semesters of such activities (spring of $6^{\text {th }}$ grade through spring of $8^{\text {th }}$ grade). None of the analyses suggested that "dose" of public commitment activities significantly impacted study outcomes.

\section{Discussion}

We examined whether making a public commitment to program goals in a school-based intervention to reduce obesity predicted improved study outcomes. We found that the intervention had a significant effect on the prevalence of obesity within the group that participated in public commitment activities, although there was no intervention effect within the group that did not participate in public commitment activities. Consistent with the main outcome findings from the overall HEALTHY study [37], the effect was magnified among the subgroup of students who were overweight at baseline. Within the intervention schools, the group not participating in public commitment activities were nearly as likely to be obese ( $\geq 95^{\text {th }}$ BMI percentile) as the control group. These results indicate that participating in public commitment activities during the HEALTHY study may have potentiated changes promoted by the behavioral, nutrition, and physical activity intervention components.

Importantly, there were no substantive differences in measured baseline characteristics between the group that participated in public commitment activities and the group that did not, suggesting that these results were not an artifact of differences in measured variables at study onset. This finding was not altogether expected, as we anticipated that students who had close family members 
with diabetes or who were healthier at onset (e.g., not overweight/obese, better reported dietary and physical activity patterns) might have been more likely to participate in study activities and elect to join the PC group. Interestingly, it appeared that the act of participationrather than amount of participation-in public commitment activities was the critical factor in affecting outcomes. Students with multiple semesters, compared to a single semester, of public commitment participation demonstrated no better outcomes.

Review of our process data supported our assumption that participation in SPC and SGM activities demonstrated a public commitment to program goals. The communications campaign was designed to shift social norms and create a positive image of the intervention as a whole; interview testimony showed clear recognition throughout the student body regarding SPCs' visibility as well as evidence of their effectiveness as agents of influence. Moreover, the considerable increase in awareness of study posters following the introduction of student-generated media highlighted the salience of these images. Nonetheless, we wish to emphasize the importance of the core intervention elements (nutrition and physical activity offerings as well as behavioral change campaigns) in building the foundation for such changes. We are skeptical that the implementation of public commitment activities such as those described here would contribute to a lower prevalence of obesity in the absence of these core elements.

Our findings are consistent with others who have reported that peer leadership participation results in better health-related outcomes than participation in the core intervention only [33,52-54]; although, to our knowledge, none of these previous studies included a student-generated media component, nor did they examine findings within the framework of the influence of public commitment activities. Indeed, our finding that activity dose was not related to outcome suggested that it was the commitment per se rather than the potential added exposure to the intervention that was associated with the observed lower prevalence of obesity.

With the greater reduction in obesity prevalence within the group participating in public commitment activities, we expected to see some changes in the hypothesized mediators; namely, improved fitness and dietary intake. No such differences were detected. Our observations may have been restricted by the limited sensitivity of our dietary intake and physical activity assessment measures (Block Kids FFQ; 20-meter shuttle run). More sensitive measures might have revealed mechanisms that affected obesity prevalence. Future studies may benefit from more sensitive assessments in evaluating proposed mediators of change.

Some caution should be exercised in generalizing from the present study, as the findings are exploratory and post-hoc. As such we characterize the analyses presented here as "hypothesis generating" suggesting that an important next step is replicating the study using a fully powered "hypothesis testing" design. In addition, our analysis did not discriminate between the impact of the different modes of public commitment on study outcomes. Future studies may want to examine the impact of the various types of public commitment activities separately (e.g., peer leadership and student-generated media). Further, we can not rule out that differences in outcomes may have been due to unmeasured factors (e.g., prosocial behavior that motivated student participation in these public commitment activities as well as uptake of HEALTHY behavioral targets). Finally, an inherent limitation of the research is the non-randomized nature of the "public commitment" assignment. While conceivably a study design (however cost-prohibitive) could randomly assign students to public-commitment activities, we suspect that the voluntary nature of this undertaking is important and perhaps inherent to its success.

As concern about youth obesity continues to mount, widespread policy changes supporting behavior-change initiatives and nutritional and physical activity offerings in schools may have enhanced impact with the inclusion of the incremental benefit of public commitment activities. Sustaining public commitment activities in everyday school settings (without the support of a clinical trial) would require a teacher or school administrator to organize the opportunities for such activities yet the program itself requires little investment. This approach is also likely to be implementable across a broad range of schools and communities as the largely student led nature of such activities ensures that youth experiences and sensibilities in a given setting are accurately reflected in a manner that would not be possible with a more centrally based communications approach. The next step for such research may involve randomizing schools to receive the additional element of public commitment activities on top of publicly funded and mandated obesity prevention programs. We found that working within a middle school environment, there were often administrative, pragmatic and/or safety concerns that limited our ability to use a broader set of technologies and social media to further student options, particularly ones that would be acceptable across all 21 of the intervention schools. This experience suggests that single-site studies may be able to employ more innovative means to further student-generated opportunities for program involvement thereby perhaps potentiating the effect of such public commitment activities on health outcomes.

\section{Conclusions}

As concern about youth obesity continues to mount, there is increasing consideration of widespread policy changes to support improved nutritional and enhanced 
physical activity offerings for middle school students - a development period of heightened risk for the development of obesity and consequently an important opportunity for prevention. Our research suggests that a critical element in the success of such programs may be to involve students as spokespeople for the program. Making such a public commitment to healthy lifestyle program targets (improved nutrition and enhanced physical activity) may potentiate healthy behavior changes among such students and provide a model for their peers.

\section{Acknowledgements}

We wish to thank the administration, faculty, staff, students, and their families at the middle schools and school districts that participated in the HEALTHY study.

This work was completed with funding from NIDDK/NIH grant numbers U01-DK61230, U01-DK61249, U01-DK61231, and U01-DK61223 to the STOPPT2D collaborative group.

The following individuals and institutions constitute the HEALTHY Study Group (* indicates principal investigator or director): Study Chair Childrens Hospital Los Angeles: F.R. Kaufman Field Centers Baylor College of Medicine: T. Baranowski*, L. Adams, J. Baranowski, A. Canada, K.T. Carter, K.W. Cullen, M.H. Dobbins, R. Jago, A. Oceguera, A.X. Rodriguez, C. Speich, L.T. Tatum, D. Thompson, M.A. White, C.G. Williams Oregon Health \& Science University: L. Goldberg*, D. Cusimano, L. DeBar, D. Elliot, H.M. Grund, S. McCormick, E. Moe, J.B. Roullet, D. Stadler Temple University: G. Foster* (Steering Committee Chair), J. Brown, B. Creighton, M. Faith, E.G. Ford, H. Glick, S. Kumanyika, J. Nachmani, L. Rosen, S. Sherman, S. Solomon, A. Virus, S. Volpe, S. Willi University of California at Irvine: D. Cooper*, S. Bassin, S. Bruecker, D. Ford, P. Galassetti, S. Greenfield, J. Hartstein, M. Krause, N. Opgrand, Y. Rodriguez, M. Schneider University of North Carolina at Chapel Hill: J. Harrell*, A. Anderson, T. Blackshear, J. Buse, J. Caveness, A. Gerstel, C. Giles, W. Hall, A. Jessup, P. Kennel, R. McMurray, A-M. Siega-Riz, M. Smith, A. Steckler, A. Zeveloff University of Pittsburgh: M.D. Marcus*, M. Carter, S. Clayton, B. Gillis, K. Hindes, J. Jakicic, R. Meehan, R. Noll, J. Vanucci, E. Venditti University of Texas Health Science Center at San Antonio: R. Treviño*, A. Garcia, D. Hale, A. Hernandez, I. Hernandez, C. Mobley, T. Murray, J. Stavinoha, K. Surapiboonchai, Z. Yin Coordinating Center George Washington University: K. Hirst*, K. Drews, S. Edelstein, L. El ghormli, S. Firrell, M. Huang, P. Kolinjivadi, S. Mazzuto, T. Pham, A. Wheeler Project Office National Institute of Diabetes and Digestive and Kidney Diseases: B. Linder*, C. Hunter, M. Staten Central Biochemistry Laboratory University of Washington Northwest Lipid Metabolism and Diabetes Research Laboratories: S.M. Marcovina*

HEALTHY intervention materials are available for download at http://www. healthystudy.org/.

Past and present HEALTHY study group members on the social-marketing based communications committee on whose work this report was based were: Lynn DeBar (Chair), Tara Blackshear, Jamie Bowen, Sarah Clayton, Tamara Costello, Kimberly Drews, Eileen Ford, Angela Garcia, Katie Giles, Bonnie Gillis, Healthy Murphy Grund, Art Hernandez, Ann Jessup, Megan Krause, Barbara Linder, Jeff McNamee, Esther Moe, Chris Nichols, Margaret Schneider, Brenda Showell, Sara Solomon, Diane Stadler, Mamie White, and Alissa Wheeler. The committee was supported by the creative teams at the Academy for Educational Development and Planit Agency. We attest that everyone who contributed substantially to the study has been included in these acknowledgements.

\section{Author details}

'Kaiser Permanente Center for Health Research, 3800 North Interstate Ave, Portland, OR 97227, USA. '2Department of Planning, Policy, and Design, University of California at Irvine, 258 Social Ecology I, Irvine, CA 92697, USA. ${ }^{3}$ The George Washington University Biostatistics Center, 6110 Executive Blvd, Suite 750, Rockville, MD 20852, USA. The Children's Hospital of Philadelphia, Department of Pediatrics, 3535 Market Street, Suite 1572, Philadelphia, PA 19104, USA. ${ }^{5}$ Division of Health Promotion and Sports Medicine, Oregon Health \& Science University, 3181 SW Sam Jackson Park Road, CR110,
Portland, OR 97239, USA. ${ }^{6}$ Children's Nutrition Research Center, Baylor College of Medicine, 1100 Bates Street \#2033, Houston, TX 77030, USA. ${ }^{7}$ College of Education, Texas A\&M University, Corpus Christi, 6300 Ocean Drive, Unit 5818, Corpus Christi, TX 78412, USA. ${ }^{8}$ City of Philadelphia Department of Public Health, 1101 Market Street, Floor 9, Philadelphia, PA 19102, USA. 'School of Nursing, The University of North Carolina at Chapel Hill, Carrington Hall, CB \#7460, Chapel Hill, NC 27599-7460, USA. ${ }^{10}$ University of Pittsburgh, Western Psychiatric Institute and Clinic, 3811 O'Hara St., Pittsburgh, PA 15213, USA.

\section{Authors' contributions}

LLD led the development and revision of the manuscript. KLD preformed the analyses and led the interpretation of the data. LLD, MS, and KLD played a major role in the revision of the manuscript for intellectual content. LLD, $M S, K L D, E G F, D D S, E L M, M W, A E H, S S, A J$ were responsible for conception and design of the communications component of the HEALTHY study. All authors participated in the implementation of the study, interpretation of data, and development and revision of the manuscript. All authors read and approved the final manuscript.

\section{Competing interests}

The authors declare that they have no competing interests.

Received: 21 April 2011 Accepted: 20 September 2011

Published: 20 September 2011

\section{References}

1. Ogden $\mathrm{CL}$, Carroll MD, Curtin LR, Lamb MM, Flegal KM: Prevalence of high body mass index in US children and adolescents, 2007-2008. Journal of the American Medical Association 2010, 303:242-249.

2. Gordon-Larsen P, Adair LS, Popkin BM: The relationship of ethnicity, socioeconomic factors, and overweight in US adolescents. Obesity Research 2003, 11:121-129.

3. HEALTHY Study Group, Kaufman FR, Hirst K, Linder B, Baranowski T, Cooper DM, Foster GD, Goldberg L, Harrell JS, Marcus MD, Treviño RP: Risk factors for type 2 diabetes in a sixth- grade multiracial cohort: the HEALTHY study. Diabetes Care 2009, 32:953-955.

4. Institute of Medicine, Committee on Prevention of Obesity in Children and Youth, Food and Nutrition Board, Board on Health Promotion and Disease Prevention: Preventing Childhood Obesity: Health in the Balance Washington DC: National Academies Press; 2005

5. Weiss R, Dziura J, Burgert TS, Tamborlane WW, Taksali SE, Yeckel CW, Allen K, Lopes M, Morrison J, Sherwin RS, Caprio S: Obesity and the metabolic syndrome in children and adolescents. New England Journal of Medicine 2004, 350:2362-2374.

6. Baranowski T, Cullen KW, Nicklas T, Thompson D, Baranowski J: Schoolbased obesity prevention: a blueprint for taming the epidemic. American Journal of Health Behavior 2002, 26:486-493.

7. Katz DL, O'Connell M, Njike VY, Yeh MC, Nawaz H: Strategies for the prevention and control of obesity in the school setting: systematic review and meta-analysis. International Journal of Obesity (Lond) 2008, 32:1780-1789.

8. Foster GD, Sherman S, Borradaile KE, Grundy KM, Vander Veur SS, Nachmani J, Karpyn A, Kumanyika S, Shults J: A policy-based school intervention to prevent overweight and obesity. Pediatrics 2008, 121:e794-e802.

9. James J, Thomas P, Cavan D, Kerr D: Preventing childhood obesity by reducing consumption of carbonated drinks: cluster randomised controlled trial. British Medical Journal 2004, 328:1237.

10. Gortmaker SL, Peterson K, Wiecha J, Sobol AM, Dixit S, Fox MK, Laird N: Reducing obesity via a school-based interdisciplinary intervention among youth: Planet Health. Archives of Pediatric and Adolescent Medicine 1999, 153:409-418

11. Luepker RV, Perry CL, McKinlay SM, Nader PR, Parcel GS, Stone EJ, Webber LS, Elder JP, Feldman HA, Johnson CC, Kelder SH, Wu M, CATCH Collaborative Group: Outcomes of a field trial to improve children's dietary patterns and physical activity. The Child and Adolescent Trial for Cardiovascular Health. CATCH collaborative group. Journal of the American Medical Association 1996, 275:768-776.

12. Caballero B, Clay T, Davis SM, Ethelbah B, Rock BH, Lohman T, Norman J, Story M, Stone EJ, Stephenson L, Stevens J, Pathways Study Research Group: Pathways: a school-based, randomized controlled trial for the 
prevention of obesity in American Indian schoolchildren. American Journal of Clinical Nutrition 2003, 78:1030-1038

13. Cialdini RB, Cacioppo JT, Bassett R, Miller JA: Low-ball procedure for producing compliance: Commitment then cost. Journal of Personality and Social Psychology 1978, 36:463-476.

14. Gopinath M, Nyer PU: The effect of public commitment on resistence to persuasion: The influence of attitude certainity, issue importance, susceptibility to normative influence, preference for consistency, and source proximity. International Journal of Research in Marketing 2009, 26:60-68.

15. Kiesler CA: The Psychology of Commitment New York: Academic Press; 1971.

16. Leake R, Friend R, Wadhwa N: Improving adjustment to chronic illness through strategic self-presentation: an experimental study on a renal dialysis unit. Health Psychology 1999, 18:54-62.

17. Salancik GR: Commitment and the Control of Organizational Behavior and Belief St. Clair Press; 1977, 6.

18. Hollenbeck JR, Williams CR, Klein HJ: An empirical examination of the antecedents of commitment to difficult goals. Journal of Applied Psychology 1989, 74:18-23.

19. Stults DM, Meese LA: Behavioral consistency: The impact of public versus private statements of intentions. Journal of Applied Social Psychology 1985, 125:277-278

20. McCaul KD, Hinsz VB, McCaul HE: The effects of commitment to performance goals on effort. Journal of Applied Social Psychology 1987, 17:437-451.

21. Hayes SC, Rosenfarb I, Wulfert E, Munt ED, Korn Z, Zettle RD: Selfreinforcement effects: An artifact of social standard setting? Journal of Applied Behavioral Analysis 1985, 18:201-214.

22. Wilson DK, Friend R, Teasley N, Green S, Reaves IL, Sica DA: Motivational versus social cognitive interventions for promoting fruit and vegetable intake and physical activity in African American adolescents. Annals of Behavioral Medicine 2002, 24:310-319, quote from p. 311.

23. Festinger L: A Theory of Cognitive Dissonance Evanston, IL: Row, Peterson; 1957.

24. Brehm JW, Cohen AR: Explorations on Cognitive Dissonance New York: Wiley; 1962.

25. Rhodewalt F, Agustsdottir S: Effects of self-presentation on the phenomenal self. Journal of Personality and Social Psychology 1986, 50:47-55.

26. Lewin K: Group decisions and social change. In Readings in Social Psychology. Edited by: Maccoby EE, Newcomb TM, Hartley EL. New York: Holt; 1958:197-212.

27. Lewin K: Forces behind food habits and methods of change. Bulletin of the National Research Council 1943, 108:35-65.

28. Radke M, Klisurich D: Experiments in changing food habits. Journal of the American Dietetic Association 1947, 24:190-207.

29. Kulik JA, Carlino P: The effect of verbal commitment and treatment choice on medication compliance in a pediatric setting. Journal of Behavioral Medicine 1987, 10:367-376.

30. de Vries H, Dijk F, Wetzels J, Mudde A, Kremers S, Ariza C, Vitória PD, Fielder A, Holm K, Janssen K, Lehtovuori R, Candel M: The European Smoking prevention Framework Approach (ESFA): effects after 24 and 30 months. Health Education Research 2006, 21:116-132.

31. Hurd PD, Johnson CA, Pechacek T, Bast LP, Jacobs DR, Luepker RV: Prevention of cigarette smoking in seventh grade students. Journal of Behavioral Medicine 1980, 3:15-28.

32. Perry $\mathrm{CL}$, Kelder SH, Murray DM, Klepp Kl: Communitywide smoking prevention: long-term outcomes of the Minnesota Heart Health Program and the Class of 1989 Study. American Journal of Public Health 1992, 82:1210-1216

33. Birnbaum AS, Lytle LA, Story M, Perry CL, Murray DM: Are differences in exposure to a multicomponent school-based intervention associated with varying dietary outcomes in adolescents? Health Education and Behavior 2002, 29:427-443.

34. DeBar LL, Schneider M, Ford EG, Hernandez AE, Showell B, Drews KL, Moe EL, Gillis B, Jessup AN, Stadler DD, White M, HEALTHY Study Group: Social marketing-based communications to integrate and support the HEALTHY study intervention. International Journal of Obesity (Lond) 2009, 33(Suppl 4):S52-S59.

35. HEALTHY Study Group, Hirst K, Baranowski T, Debar L, Foster GD, Kaufman F, Kennel P, Linder B, Schneider M, Venditti EM, Yin Z: HEALTHY study rationale, design and methods: moderating risk of type 2 diabetes in multi-ethnic middle school students. International Journal of Obesity (Lond) 2009, 33(Suppl 4):S4-20.

36. Murray DM: Design and Analysis of Group-Randomized Trials New York: Oxford University Press; 1998

37. HEALTHY Study Group, Foster GD, Linder B, Baranowski T, Cooper DM Goldberg L, Harrell JS, Kaufman F, Marcus MD, Treviño RP, Hirst K: A schoolbased intervention for diabetes risk reduction. New England Journal of Medicine 2010, 363:443-453

38. Venditti EM, Elliot DL, Faith MS, Firrell LS, Giles CM, Goldberg L, Marcus MD, Schneider M, Solomon S, Thompson D, Yin Z, HEALTHY Study Group: Rationale, design and methods of the HEALTHY study behavior intervention component. International Journal of Obesity (Lond) 2009, 33(Suppl 4):S44-S51.

39. Gillis B, Mobley C, Stadler DD, Hartstein J, Virus A, Volpe SL, El ghormli L, Staten MA, Bridgman J, McCormick S, HEALTHY Study Group: Rationale, design and methods of the HEALTHY study nutrition intervention component. International Journal of Obesity (Lond) 2009, 33(Suppl 4): S29-S36.

40. McMurray RG, Bassin S, Jago R, Bruecker S, Moe EL, Murray T, Mazzuto SL, Volpe SL, HEALTHY Study Group: Rationale, design and methods of the HEALTHY study physical education intervention component. International Journal of Obesity (Lond) 2009, 33(Suppl 4):S37-S43.

41. Drews KL, Harrell JS, Thompson D, Mazzuto SL, Ford EG, Carter M, Ford DA, Yin Z, Jessup AN, Roullet JB, HEALTHY Study Group: Recruitment and retention strategies and methods in the HEALTHY study. International Journal of Obesity (Lond) 2009, 33(Suppl 4):S21-S28.

42. Schneider M, Hall WJ, Hernandez AE, Hindes K, Montez G, Pham T, Rosen L, Sleigh A, Thompson D, Volpe SL, Zeveloff A, Steckler A, HEALTHY Study Group: Rationale, design and methods for process evaluation in the HEALTHY study. International Journal of Obesity (Lond) 2009, 33(Suppl 4): S60-S67.

43. Diggle P, Heagerty P, Liang KY, Zeger SL: Analysis of Longitudinal Dato Oxford: Oxford University Press; 2002.

44. Molenberghs G, Verbeke G: Models for Discrete Longitudinal Data New York: Springer; 2005

45. Donner A, Klar N: Design and Analysis of Cluster Randomization Trials in Health Research London: Arnold Publishers; 2000.

46. Petersen AC, Tobin-Richards M, Boxer A: Puberty: its measurement and its meaning. Journal of Early Adolescence 1983, 3:47-62.

47. Petersen $A C$, Crockett $L$, Richards $M$, Boxer $A$ : A self-report measure of pubertal status, reliability, validity, and initial norms. Journal of Youth and Adolescence 1988, 17:117-133.

48. Robertson EB, Skinner ML, Love MM, Elder GH, Conger RD, Dubas JS, Petersen AC: The pubertal development scale: A rural and suburban comparison. Journal of Early Adolescence 1992, 12:174-186.

49. Shaffer JP: Modified sequentially rejective multiple test procedures. Journal of the American Statistical Association 1986, 81:826-831.

50. Welk G, Morrow J: Interpreting Fitnessgram Results. Fitnessgram/ Activitygram Test Administration Manual. Fourth edition. Champaign, IL: Human Kinetics; 2007, 59-68.

51. Beets M, Pitetti K: Criterion-referenced reliability and equivalency between the PACER and 1-mile run/walk for high school students. Journal of Physical Activity \& Health 2006, 3(Suppl 2):S21-S33.

52. Black BC, Bull S, Smith LM, Ciao AC: Effects of being a peer-leader in an eating disorder prevention program: can we further reduce eating disorder risk factors? Eating Disorders 2008, 16:444-459.

53. Komro KA, Perry CL, Murray DM, Veblen-Mortenson S, Williams $C L$, Anstine PS: Peer-planned social activities for preventing alcohol use among young adolescents. Journal of School Health 1996, 66:328-334.

54. Sawyer RG, Pinciaro P, Bedwell D: How peer education changed peer sexuality educators' self-esteem, personal development, and sexual behavior. Journal of American College Health 1997, 45:211-217.

\section{Pre-publication history}

The pre-publication history for this paper can be accessed here: http://www.biomedcentral.com/1471-2458/11/711/prepub

doi:10.1186/1471-2458-11-711

Cite this article as: DeBar et al:: Student public commitment in a school-based diabetes prevention project: impact on physical health and health behavior. BMC Public Health 2011 11:711. 